\title{
Management and financing of post-closure liabilities
}

\author{
K.A. Bocking Golder Associates Ltd., Canada \\ P. Fitzgerald Mine Closure Services LIp, Canada
}

\begin{abstract}
At many mine sites, the implementation of planned closure measures will not result in the desired 'walkaway' scenario. After a mining company spends all their capital expenditures and completes their promised closure measures, they may still have ongoing liabilities and risks, which could vary from simple routine care and maintenance of the site to ongoing treatment of effluent to 'risk costs' associated with the potential for earthquakes or floods.
\end{abstract}

Where such liabilities continue to exist after closure, it will be necessary to make definitive arrangements for the ongoing management of the mine site in the long term, if not perpetually. Such site management will carry costs, so it will also be necessary to have sustainable financing in place. It is clear that mining companies do not last forever; therefore the management arrangements and financing must be sustainably independent of the existence of the mining company.

Many jurisdictions have provisions for closed mining properties to be 'returned to the crown'. Where this occurs, the responsible government will also have to make similar arrangements for the long term management and financing of a portfolio of returned sites.

This paper gives examples of post-closure liabilities and costs. It also discusses using risk modelling to estimate future costs and discusses alternative approaches for long term sustainable financing.

\section{Introduction}

Over the past 20 years, closure planning has become an integral part of most mining projects. During that period, mine closure regulations have been promulgated in many jurisdictions throughout the world, wherever mining is active. Typically, these regulations were written on the presumption that the implementation of closure measures would result in a walk-away condition, such that all of the outstanding liabilities associated with a particular mining property would be resolved. After that, the financial assurance could be released, the mining lease could be extinguished and the closed property could be returned to the governmental authority. This is often referred to as a 'return to the crown' in countries with monarchies.

Experience has shown that most mines do not actually attain walk-away conditions. Furthermore, very few have ever been successfully been returned to the crown. As a result, there is a large inventory of mines that are 'in limbo' in that they still have significant liabilities and remain in the hands of the mining companies. A structure is required to manage these properties on an ongoing basis and to financially assure the liabilities associated with them.

\section{The need for post-closure management and financing}

The actual experience of mine closures is distinctly at odds with the presumed scenario of walk-away conditions being achieved followed by an 'return to the crown'. In fact, the majority of closed mine sites still have some form of unresolved liabilities associated with them. Typical examples of ongoing liabilities and risks that may continue in the post-closure period include requirements for the following:

- Periodic inspections and reporting.

- Routine care and maintenance of the site. 
- Ongoing treatment of effluent, in some cases this may even be required perpetually.

- Hazards to the public safety related to unstable crown pillars, open pit slopes, etc.

- 'Risk costs' associated with the potential for catastrophic failures, in some cases due to unexpected events, such as floods and earthquakes.

- Delayed liabilities such as open pits that flood slowly and then overflow.

- Costs associated with ongoing beneficial use of the reclaimed land.

Post-closure liabilities are described in more detail in Bocking et al. (2009).

The authors are aware of only a handful of properties that have been successfully closed out and then returned to the crown. Several case histories of successful relinquishment are described by Butler and Bentel (2011). Unfortunately, the number of successes is very small and, as a result, there is a large and growing inventory of closed mining properties that still have unresolved liabilities and that remain on the books of mining companies. There are also many properties that have reverted to the crown in an unsatisfactory manner due to the insolvency of the mining company that previously held the mining rights. Cowan et al. (2010) report that there are now over 10,000 orphaned or abandoned mines in Canada alone.

Even in the few instances where closed mining properties have been successfully 'returned to the crown', it is still necessary to make arrangements for the closed mining properties within the governmental portfolio to be inspected, and managed. In other words, the residual liabilities associated with the former mining properties still exist; it is only the responsible party that has changed. Cowan et al. (2010) provides a detailed discussion of the conditions associated with a 'return to crown' and also discusses the framework for post-closure property management put forward in several jurisdictions.

Where unresolved liabilities continue to exist after closure measures are implemented, it will be necessary to make definitive arrangements for the ongoing management of the mine site in the long term, if not perpetually). There will be significant costs associated with such site management; consequently it will be necessary to have sustainable financing in place. It is also clear that mining companies do not last forever, therefore the management arrangements and financing must be sustainably independent of the continued existence of the mining company.

\section{Use of environmental risk financing}

By default, most closed-out mining properties remain in the hands of mining companies. This is not a desirable outcome for the companies because it leaves them with unresolved liabilities with respect to properties that may have little or no remaining commercial value. They will likely incur costs on an ongoing basis for the inspection and routine maintenance of the property at the very least. They are also at some risk of facing large expenditures should low probability events occur, such as a tailings dam failure caused by an extreme flood or a large seismic event. Depending on accounting rules in the jurisdiction where their stock is listed, they may also have to report some of these unresolved liabilities as ongoing asset retirement obligations on their books. Risk modelling provides a means of estimating an appropriate level of internal funding to cover the future management of retained closed properties.

Fortunately, there are well-established environmental risk financing structures that can respond to all potential mine closure and post-closure liabilities at a mine site. These structures can be customised to comply with even the most stringent regulatory regimes, while still allowing the mine owner to achieve a permanent release of the permit obligations and indemnity for all future legal liabilities - 'a responsible exit', so to speak.

A mine owner seeking a responsible exit from a closed mine may consider the advantages of creating and funding an Environmental Risk Financing (ERF) programme, perhaps within an arms-length Special Purpose Company (SPC) that can provide a complete indemnity to the owner and a financial assurance to the regulator. This would involve a payment of funds from the mining company to the SPC. The SPC would then 
use the funds to assume the management responsibility for all aspects of the mine closure/post-closure obligations including posting the financial assurance and retaining contractors and professional advisory services to mitigate the risks. The objective is to achieve complete closure and finally to implement a postclosure plan that is funded, in perpetuity if necessary, so that permits are released and financial assurance is returned.

The cornerstone of an ERF programme is an Alternative Risk Transfer (ART) structure that has adequate funds to effectively manage the closure/post-closure tasks and also to purchase a suite of environmental insurance products that will cap and guarantee the liabilities.

Properly designed and fully funded, this ERF ART structure will enable a mine owner to transfer the liabilities and to contract all closure and post-closure obligations to a qualified third party with controls and incentives to ensure the highest standards of performance.

\section{$4 \quad$ The environmental risk financing structure}

The ART markets are comprised of the largest and highest-rated international insurers and re-insurers with specialised underwriting expertise and capacity. These insurers are primarily located in off-shore, low-tax domiciles - Bermuda being the preferred domicile for this type of underwriting capacity.

A properly structured ART programme will have the following features:

- Project specific - the risk components will be priced based on a detailed risk assessment of the specific mining property.

- Transparent - the various components of risk will be priced separately and then consolidated into a single programme.

- Profit-sharing - the programs will require conservative funding estimates, therefore there must be a mechanism for returning or sharing unused funds that become surplus upon successful completion of a project.

- Long-term stability - the risk financing structure must survive the liabilities and indemnities offered. The structure must also remain in place if the mining company ceases to exist.

To achieve a liability transfer, it may be necessary to place the closure funds in a SPC such as a whollyowned captive insurer. The amount of the closure funds will be determined by a net present value (NPV) assessment of the expected costs of all closure/post closure obligations, plus the insurance premium costs for the appropriate application of environmental insurance products that are required to protect the SPC from worst case loss scenarios and the possibility of unexpected and sometimes catastrophic events. The funds and insurance premiums would be invested by the insurer to yield a positive cash flow to support the future costs.

The ART structure is likely to include some or all of the following insurances at some stage during the closure and post closure phases:

- Cost cap insurance to respond to over-runs of projected remediation budgets.

- Pollution Legal Liability (PLL) insurance to respond to owners' liability to others caused by unexpected pollution events.

- Early closure cover to respond to a funding shortfall caused by the early closure of a mine.

- Professional liability (errors and omissions) and contractor's pollution insurance to respond to the negligence of others working on a closure project.

- Surety reclamation bond to provide a performance guarantee as required by the mine regulator.

A typical risk financing structure is shown in Figure 1. 


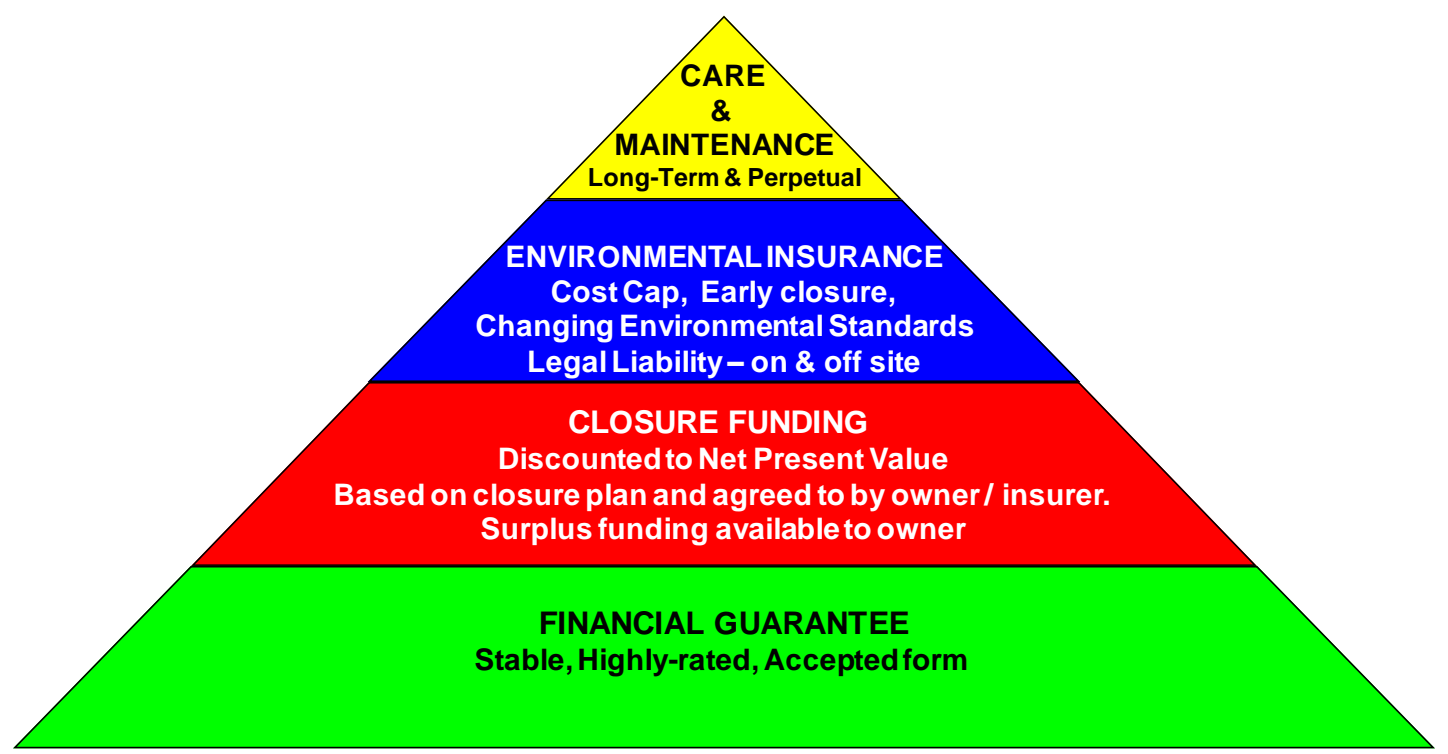

Figure 1 Environmental risk financing structure for mine closure

\section{$5 \quad$ Estimating the residual risk of post-closure}

There are a number of options available to the mine owner and the third party SPC manager for managing the residual risks once closure is completed, but all options must lead to the ultimate goal of achieving a full and final release of the site obligations from the regulator.

A perpetual care annuity for a mine may carry more risk than one for a cemetery plot, but the concept is the same and the risk can be wrapped up in a similar financial arrangement. Planned post-closure activities such as care and maintenance in perpetuity can be estimated and funded at NPV. Residual liabilities, including unexpected and even catastrophic events, can be estimated through a site specific risk assessment process and a complex risk modelling approach (Bocking, 2010).

Risk assessment is increasingly being used as a tool to evaluate residual liabilities for closed mining facilities. The risk assessment is usually conducted by an expert panel and includes three steps:

1. Hazard identification (failure modes).

2. Risk analysis (severity and likelihood of failure).

3. Risk evaluation (risk acceptance and mitigation).

Expert judgement is commonly used to provide input into the model with respect to the following: (i) the consequences of extreme events; (ii) the threshold at which damage first occurs; and (iii) the likelihood of its occurrence. The risk evaluation matrix considers environmental, safety, regulatory and financial impacts of the failure and forms a basis for actions to mitigate the risk.

Post-closure liabilities are ultimately integrated in a 'Monte Carlo' type of computer model and they are expressed in terms of cost. While it is still common place to calculate a single value of expected post-closure cost, there is a growing recognition that the cost estimate itself is inherently variable. A probabilistic based cost estimate can provide a more robust answer. The results are expressed as an 'S-shaped' curve of cost versus the probability of exceedence. Figure 2 shows typical probabilistic cost predictions. 


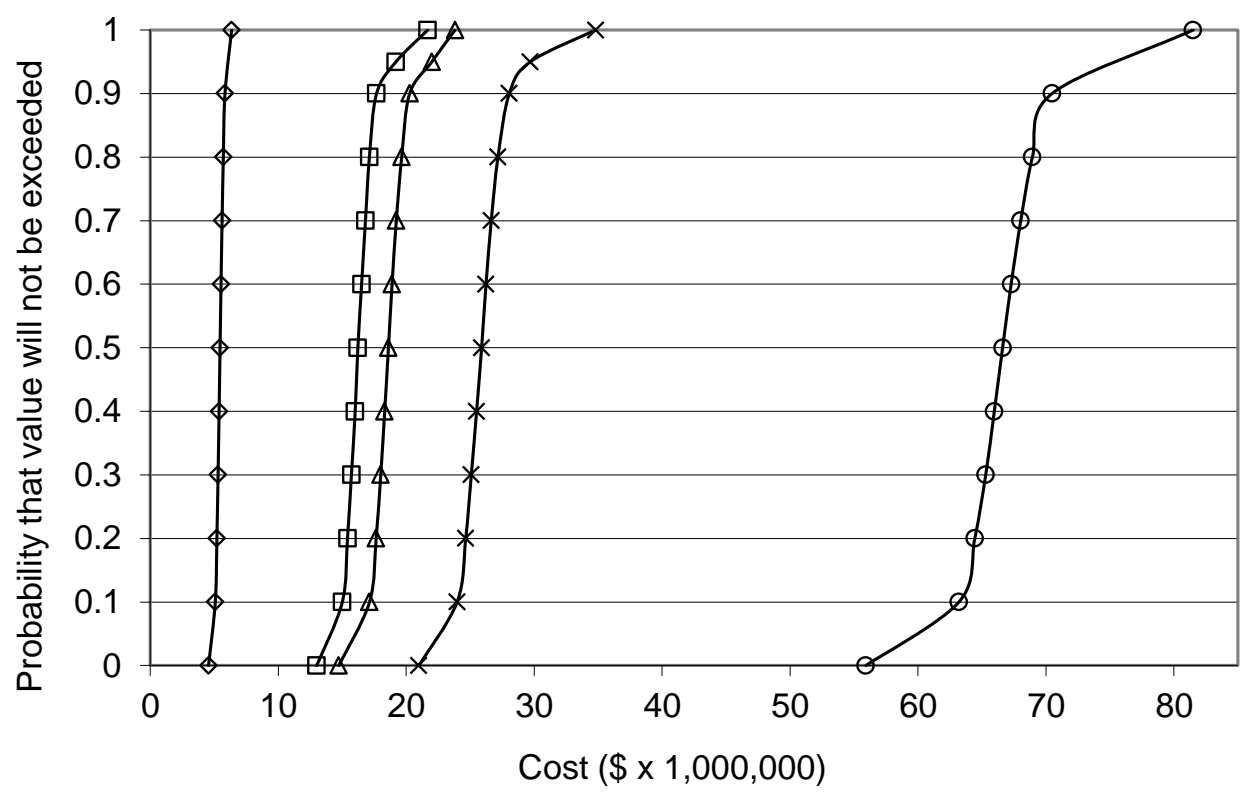

\section{Figure 2 Typical stochastic predications of care and maintenance costs for five tailings areas}

Based on stochastic simulation with cost parameters that have predetermined probabilistic distribution functions, the cost model can answer questions such as, "how much money does a mining company need to put aside to satisfy the outstanding liabilities $50 \%$ of the time?"

The process of computing the likely range of overall costs and also the distribution of each individual cost component can itself be very instructive in the overall closure planning process. It can indicate cost effective actions that can reduce the liability. For example, the construction of a back-up 'dry spillway' in an impoundment can reduce the consequences of plugging of the main service spillway. The reduced consequence reduces the risk and therefore lowers the total probabilistic liability. In short, risk modelling can serve as an invaluable tool to help manage the outstanding liabilities.

The post-closure annuity must be based on credible and thoroughly assessed risk data that a remediation contractor and ultimately a regulator will accept as the full and final funding mechanism for the post-closure liabilities.

\section{$6 \quad$ Case study}

The following case study illustrates the requirements for implementing a liability transfer agreement. A large mining company engaged an environmental remediation contractor to acquire seven closed mine properties located in close proximity. The closure plans and budgets had been developed and agreed upon by the parties to the transaction. The risk financing structure was designed to achieve the following objectives which would permit the owner to effectively transfer the liability to a responsible party (in this case a remediation contractor):

- To fully fund and transfer the budgeted closure liability.

- To fully fund and transfer the perpetual closure obligations.

- To insure fortuitous or unexpected events such as closure cost overruns and, sudden/accidental pollution events.

- To provide financial assurance of closure to the mine regulator.

- To remove the closure provision from the owner's corporate balance sheet.

- To expense the entire program cost for tax purposes. 
This risk financing structure anticipated a one-time premium payment at inception with profit-sharing incentives for the remediation contractor and other partners, such as the insurer.

An 'owner designed' ART programme was recommended in which the proponent(s) could negotiate fully transparent pricing of the various funding/profit-sharing and risk transfer components individually from the most efficient markets and financial counter-parties.

The elements of the proposed liability transfer agreement are depicted in Figure 3.

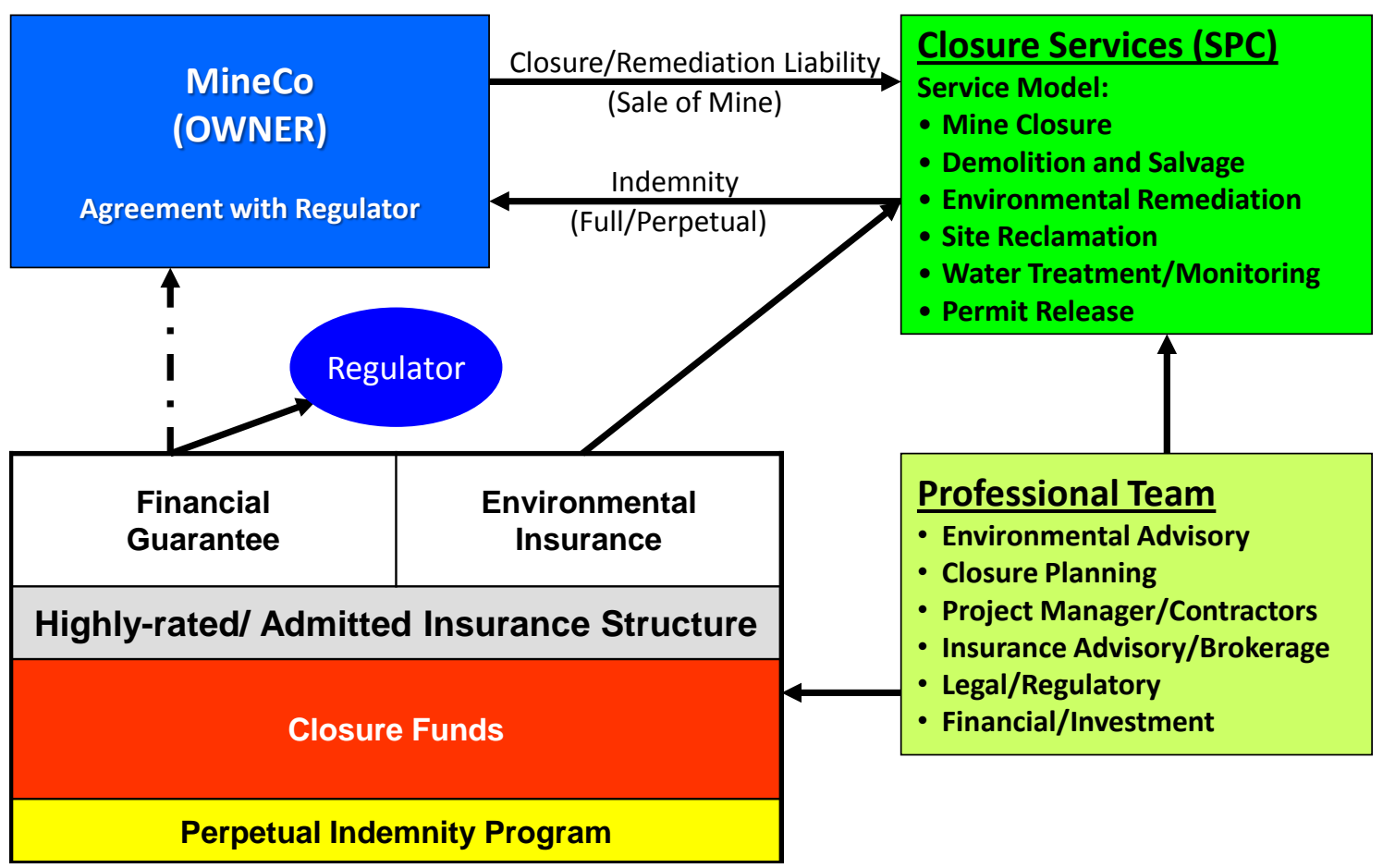

\section{Figure 3 Schematic of environmental liability risk transfer}

This case study illustrates that it is possible to establish an appropriate structure. In this particular case, the mining company decided not to pursue the environmental liability risk transfer arrangement, and it still retains ownership of the properties.

\section{$7 \quad$ Applications}

The ART financial structure will support environmental liability transfer programmes that may be applied to address various mine closure scenarios such as the following:

- To contract the closure and remediation obligations to a remediation contractor for a guaranteed price.

- To sell a mining site or portfolio of sites and the associated environmental liabilities to a responsible third party, possibly a mine operator that will resume operations or a reclamation contractor/SPC that will manage all aspects of the closure and post-closure obligation.

- To develop an enhanced financial assurance mechanism that offers many benefits to the mine owner. These programmes will guarantee that adequate financial resources are available and committed to the proper closure of a mining operation and they will also respond to unexpected, catastrophic events at the site. In this way, they more fully address the host community concerns about environmental legacies and sustainable development. 


\section{$8 \quad$ Promoting a mine sector initiative}

Implementing a liability transfer agreement is no easy task in the current regulatory regimes around the world which can impose onerous terms and conditions in their attempts to achieve a risk free mining sector. Specifically, surety bonding and insurance companies cannot be expected to comply with unrealistic demand payment terms and unending or unlimited performance obligations.

As well, host governments should not insist on protection against all unlikely events and setting the bond amount at the worst-case scenario would be an extremely risk averse strategy. One cannot expect an industry to be viable if it is subject to what appears to be overly conservative bond cost estimates (Kirschener and Grandy, 2003). Furthermore, the surety bonding market appears to be shrinking and moreover, the mining sector represents only a small portion of the surety business and therefore losses are difficult to absorb. Additionally, the long-term nature of mining risk is an attribute that is not very attractive to surety carriers (Poulin and Jacques, 2007).

A solution to this dilemma may be found by looking at other industry sectors that face similarly difficult risk issues because of their public and community obligations. The airline, nuclear and oil and gas industries each have significant financial exposures well beyond the insurance industry's capacity to provide meaningful limits and reasonable premiums. Faced with insurance market limitations, these industries have created captive insurance associations with the sole purpose of providing difficult cover exclusively to its group members.

Laval University academics, Richard Poulin and Michel Jacques, have proposed an international captive insurance company for the mining industry. An insurance captive company under the responsibility of the mining industry with compulsory membership would transfer some of the cost from the regulator to the regulated. The captive insurance company would have both technical and financial expertise. It would thus compensate for the eventual lack of expertise on the part of individual regulators. Being liable, it would not be tempted by complacency, and part of the monitoring process would be diverted from the regulator to the captive company (Poulin and Jacques, 2007).

The public is rightfully anxious to get a guarantee that rehabilitation will take place according to governmental standards. The approach used in bonding is to give an 'exit ticket' to the firm, freeing it from any further responsibility, only when all rehabilitation work has been performed. With pollution however, no-one knows for sure that all future problems have been taken care of. Notwithstanding possible complacency on the part of the regulator, the very idea of leaving the site without any future responsible party is troublesome. With a captive company, there is no need for an 'exit ticket'. In principle, the captive company will be responsible for the mining site forever (Poulin and Jacques, 2007).

\section{Conclusion}

The majority of mining properties will have residual liabilities after closure. Relatively few properties have been successfully returned to the crown. As a result, there is a large and increasing inventory of mining properties which are closed, but which have significant ongoing post-closure liabilities. For these properties, an environmental risk financing structure could enable a mine owner to transfer the liabilities and to contract all closure and post-closure obligations to a qualified third party. The structure would include appropriate insurance coverage to protect against the various types of risk associated with both closure and post-closure. It is further suggested that the mining industry as a whole should consider following other industry groups such as airlines and create a captive insurance association with the sole purpose of providing closure insurance cover exclusively to its mining group members. A properly designed and fully-funded environmental risk financing programme will meet or exceed the guidelines for corporate social responsibility, by providing a financial mechanism that will ensure there are adequate funds available for a responsible party to manage the closure and post-closure obligations of a mine and offers an effective response to community and NGO concerns about environmental legacies from mining operations. 


\section{References}

Bocking, K.A., Kam, S.N., Welch, D.E. and Williams, D.A. (2009) Management of mine sites after closure, in Proceedings Fourth International Conference on Mine Closure (Mine Closure 2009), A.B. Fourie and M. Tibbett (eds), 9-11 September 2009, Perth, Australia, Australian Centre for Geomechanics, Perth, pp. 245-252.

Bocking, K.A. (2010) Post-closure liabilities, Australian Centre for Geomechanics Newsletter, November 2010, pp. 20-23.

Butler, H. and Bentel, G. (2011) Mine relinquishment - processes and learnings, in Proceedings Sixth International Conference on Mine Closure (Mine Closure 2011), A.B. Fourie, M. Tibbett and A. Beersing (eds), 19-21 September 2011, Lake Louise, Canada, Australian Centre for Geomechanics, Perth, Vol. 2, pp. 3-12.

Cowan, W.R., Mackassey, W.O. and Robertson, J.G.A. (2010) The Policy Framework in Canada for Mine Closure and Management of Long-Term Liabilities: A Guidance Document, Prepared for National Orphaned / Abandoned Mines Initiative, November, 2010.

Kirschener, L.A. and Grandy, E.B (2003) Mining and the vanishing surety bond market, Natural Resources and Environment, Vol. 17, No. 3, pp. 152-154.

Poulin, R. and Jacques, M. (2007) Mine reclamation bonding and environmental insurance, International Journal on Risk Assessment and Management, Vol. 7, No. 5, pp. 589-606. 